\title{
La función policial desde la perspectiva de los derechos humanos y la ética pública* $^{*}$
}

\section{María José Bernal Ballesteros**}

\begin{abstract}
RESUMEN
Los altos indices de inseguridad y violencia que actualmente registran diversos paises en América Latina, asi como el abuso de la fuerza pública y las constantes violaciones a los derechos humanos, hacen necesario replantear la función policial con una perspectiva basada en los derechos humanos y en una nueva concepción de la ética pública. Este trabajo se fundamenta en la teoría de los derechos humanos; desde esta perspectiva, se aborda la función policial y se analiza la manera en que lleva a cabo esta función pública y si se apega o no a los principios constitucionales y convencionales en la materia. En contrapeso, se aborda la ética pública como una posible solución. Fortalecer el aspecto preventivo es indispensable, pues el objetivo consiste en evitar que en el ejercicio de la función policial se cometan violaciones a derechos humanos, más allá de los instrumentos de reacción y reparación con los que se cuente.
\end{abstract}

PALABRAS CLAVE

Función policial, seguridad ciudadana, derechos humanos, ética pública.

\begin{abstract}
The high rates of insecurity and violence currently registered by different Countries in Latin America, as well as the abuse of public forces and the constant violations of Human Rights, make it necessary to rethink the Police Function with a perspective based on Human Rights and a new conception of Public Ethics. This work is based on the theory of Human Rights; From this perspective, Police Function is addressed, and the way in which it carries out this Public Function is also analyzed and whether or not it adheres to the Constitution and Conventional Principles of the subject matter. In counter balance, Public Ethics is addressed as a possible solution. Strengthening the preventive aspect is essential because the objective is to prevent violations of Human Rights from being committed in the exercise of the Police Function, beyond the instruments of reaction and restitution that are available.
\end{abstract}

\section{KEYWORDS}

Police Function, Citizen Security, Human Rights, Public Ethics.

\footnotetext{
*Artículo recibido el 5 de diciembre de 2017 y aceptado para su publicación el 30 de mayo de 2018

**Titular de la Defensoría Municipal de Derechos Humanos de Toluca, México. (majo.ballesteros07@gmail.com) orcid.org/0000-0001-6090-8457
} 


\section{SUMARIO}

1. La seguridad en el siglo XXI

2. La función policial

3. Los derechos humanos en la actuación policial

4. La ética pública en la función policial

5. Reflexiones finales

\section{La seguridad en el siglo XXI}

En las sociedades del siglo xxI, la seguridad se ha colocado como una de las principales preocupaciones y demandas ciudadanas, lo mismo a nivel personal que en el ámbito público. Desde una perspectiva nacional, o bien, desde el ámbito internacional, la seguridad sigue siendo un tema pendiente en las agendas de los Estados. A nivel internacional, el interés en materia de seguridad atiende, principalmente, a los devastadores eventos que se relacionan con los movimientos masivos de personas migrantes ${ }^{1}$ y refugiadas, ${ }^{2}$ las hambrunas, las pandemias, las drogas, el crimen organizado y el terrorismo.

Por cuanto hace al ámbito interno de los Estados, los motivos que originan esta creciente demanda varían en atención a las características y contextos propios de cada sociedad. Podemos hablar, por ejemplo, de la corrupción, ${ }^{3}$ de la violencia, ${ }^{4}$ del abuso de autoridad, del uso excesivo de la fuerza pública, de los actos de tortura, ${ }^{5}$ así como otras situaciones que ponen en riesgo la dignidad y la integridad de las personas.

\footnotetext{
${ }^{1}$ De acuerdo con la onu, actualmente, se encuentran 258 millones de migrantes en todo el mundo: 48\% más que en el año 2000. "Migración: De la obsesión por los riesgos, a aprovechar las oportunidades", Noticias onu, 11 de enero, 2018. [Consulta: junio, 2018]. Disponible en: https://news.un.org/es/story/2018/01/1424892

${ }^{2}$ Según la agencia de la onu para los refugiados, el número de personas desplazadas por la fuerza incrementó a 68.5 millones, a finales de 2017. De ellas, 16.2 millones se vieron forzadas a desplazarse dentro y fuera de las fronteras de su país durante ese mismo año, lo cual justifica la magnitud de la población que se está desplazando, equivalente a 44500 personas cada día, o a una persona cada dos segundos. Alto Comisionado de las Naciones Unidas para los RefuGIADOS, "Con 68 millones de personas desplazadas, es urgente un pacto mundial sobre refugiados", Alto Comisionado de las Naciones Unidas para los Refugiados. [Consulta: junio, 2018]. Disponible en: http://www.acnur.org/noticias/ press/2018/6/5b29091d4/con-68-millones-de-personas-desplazadas-es-urgente-un-pacto-mundial-sobre.html

${ }^{3}$ De acuerdo con el Índice de Percepción de la Corrupción 2017 elaborado por Transparency International, México bajo un punto respecto del año pasado (de 30 a 29 puntos). Estos resultados evidencian que México continúa sin mejorar en el tema de corrupción. Transparency International, "Índice de Percepción de la Corrupción 2017 de Transparency International América", Transparency International, 2018. [Consulta: junio, 2018]. Disponible en: https:/I transparencia.org.es/wp-content/uploads/2018/02/america_ipc-2017.pdf

${ }^{4}$ En 2017, se registró un deterioro de la paz en 10.7\% respecto del año pasado (4.3\%) lo cual indica que 2017 fue el año más violento en México. Institute for Economics and Peace, Índice de paz México 2018, México, IeP, p. 9. [Consulta: junio, 2018]. Disponible en: http://indicedepazmexico.org/wp-content/uploads/2018/04/Indice-de-Paz-Mexico-2018.pdf

${ }^{5}$ La Unidad Especializada en Investigación del Delito de Tortura de la Procuraduria General de la República reportó
} 
Frente a este conjunto de factores de riesgo, el Estado de derecho se plantea nuevas estrategias que permitan asegurar el desarrollo y el bien común de sus gobernados. No obstante, debemos reconocer que nos encontramos frente a una enorme tarea que presenta desafíos importantes por cumplir.

La falta de satisfacción de las necesidades humanas fundamentales es otro factor que incide en la inseguridad pública. Las principales carencias que reportan los índices actuales se relacionan con la pobreza, la desigualdad y la falta de oportunidades. Burton, en su teoría de las necesidades humanas básicas, advierte que "las conductas que son respuestas a la frustración de tales necesidades frecuentemente son agresivas y contraproductivas". ${ }^{6}$ Es decir, en una sociedad donde impera la insatisfacción de las necesidades humanas básicas, ${ }^{7}$ aumenta la desviación del comportamiento humano respecto de los estándares sociales y de las normas jurídicas. En otras palabras, incrementan las conductas delictivas.

En cualquier Estado de derecho, la función policial tiene un amplio campo de acción en el tema de la seguridad. Las estrategias y vías que cada gobierno implemente respecto a sus funcionarios encargados de hacer cumplir la ley tienen una repercusión directa, ya sea positiva o negativa, en la seguridad de la ciudadanía. Por ello, previo al análisis concreto de la función policial, se ha de entender a la seguridad desde la perspectiva de los derechos humanos, es decir como un mínimo vital que requiere de medidas concretas para su garantía.

El vocablo seguridad proviene del latín securitas, que a su vez proviene del adjetivo securus: sin temor o sin temor a preocuparse. ${ }^{8}$ En una concepción personal, se trata de una condición de sentirse seguro y, en el ámbito de la administración pública, de un derecho a la seguridad ciudadana.

Tradicionalmente, a este vocablo se le ha vinculado con una interpretación policial. Sin embargo, su significación no debe ser limitativa, pues el término es neutro y supone una concepción más amplia y compleja. La seguridad

\footnotetext{
4390 casos de tortura, en revisión a nivel federal, e inició 777 investigaciones según el nuevo sistema de justicia adversarial. Amnistia InTERnACIONAL, Informe 2017/18 Amnistía Internacional. La situación de los derechos humanos en el mundo, Londres, Amnistía Internacional, 2018, p. 314. [Consulta: junio, 2018]. Disponible en: https://www. amnesty.org/es/countries/americas/mexico/report-mexico/

${ }^{6}$ Burton, Wear John, Conflict: Resolution and provention, Londres, The Macmillan Press, 1990, p. 34.

${ }^{7}$ Entre las necesidades fundamentales de carácter moral, se encuentran las relacionadas con la identidad, la autonomía, la seguridad y el desarrollo de las personas. Por su parte, entre las necesidades básicas materiales, podemos ubicar los alimentos, la salud y la vivienda. Pavarinı, Massimo, Pérez Carrillo, Agustin y Tenorio Tagle, Fernando, Seguridad Pública. Tres puntos de vista convergentes, México, Flasud - Conacyt - Ediciones Coyoacán, 2006, p. 166.

${ }^{8}$ Valencia Ramirez, Verónica Guadalupe, "La seguridad pública como derecho humano", en Certamen de ensayo sobre derechos humanos, Toluca, Comisión de Derechos Humanos del Estado de México - Legislatura del Estado de México, 2002, pp. 8-23.
} 
va mucho más allá de la protección contra la violencia y del uso de la fuerza pública; supone una protección integral de la persona ante las amenazas y vulnerabilidades de su entorno personal y público.

En palabras de Valencia Ramírez: "En un Estado democrático y progresista, la seguridad es un factor coadyuvante del bienestar social y de la calidad de vida. El desenvolvimiento de una nueva cultura y concepción de la seguridad no debe estar circunscrita únicamente a la prevención o persecución del delito, sino orientada a promover la salvaguarda y garantía de todos los derechos humanos". 9

La transición del Estado autoritario al Estado democrático produjo una evolución en el concepto de seguridad. ${ }^{10}$ Su actual significado no se preocupa únicamente por garantizar el orden como una expresión de la fuerza y supremacía del poder del Estado. La grandeza de esta nueva percepción implica ir más allá de la lucha contra la delincuencia, conlleva la exigencia de un ambiente propicio y adecuado para la convivencia pacífica. ${ }^{11}$

Desde un enfoque cronológico, el término seguridad ha sufrido múltiples transformaciones. La seguridad pública, la seguridad social, la seguridad jurídica, la seguridad humana y la seguridad ciudadana son algunas de las diversificaciones del término que han evolucionado en sincronía con los eventos históricos de la humanidad.

El primer término en aparecer fue el de seguridad pública, entendida como el conjunto de acciones encaminadas a asegurar el orden público, la integridad y los bienes de las personas. La seguridad social atendió a las constantes

\footnotetext{
${ }^{9}$ En el Estado de derecho tradicional, los ciudadanos estaban regidos por la ley, no por los hombres; en el Estado constitucional al que refiere la filosofía política alemana, se exige la existencia de instituciones bien estructuradas, de un régimen de separación y colaboración de poderes públicos que garanticen la efectividad y la generación de la misma norma jurídica. Desde esta perspectiva, la seguridad supone un marco normativo que atienda a las necesidades de cada sociedad y que de la misma manera se cuente con las instituciones, estrategias y políticas públicas necesarias para garantizar la seguridad en el ámbito personal y público. VALERO, RICARDO, "La seguridad colectiva en América Latina", en Manuel Becerra Ramírez y Nuria González Martín (coords.), Estado de Derecho Internacional, México, Universidad Nacional Autónoma de México, 2012, pp. 259-392.

${ }^{10}$ De acuerdo con Martín del Campo, México fue parte de un proceso de transición prolongada. A diferencia de otros paises como Argentina, Portugal o la entonces Unión Soviética, en México no hubo un colapso del régimen autoritario. No obstante, se produjo una disolución paulatina que permitió establecer una forma de democracia predominantemente electoral. MARTiN DEL CAMPO, LABASTIDA, JuLIO, "La transición del autoritarismo a la democracia en México", en Miguel Carbonell Sánchez, Héctor Felipe Fix-Fierro, Luis Raúl González Pérez y Diego Valadés (coords.), Estado constitucional, derechos humanos, justicia y vida universitaria. Estudios en homenaje a Jorge Carpizo. Estado constitucional, tomo 4, vol. 2, México, Universidad Nacional Autónoma de México, 2015, pp. 121-188.

${ }^{1}$ Cfr. Comisión Interamericana de Derechos Humanos, Informe sobre seguridad ciudadana y derechos humanos, Comisión Interamericana de Derechos Humanos. [Consulta: octubre, 2017]. Disponible en: http://www.cidh.org/pdf\%20files/ SEGURIDAD\%20CIUDADANA\%202009\%20ESP.pdf
} 
demandas ante los riesgos y condiciones de trabajo en la época de la industrialización. En el ámbito del derecho, se dio la seguridad jurídica como una garantía judicial. ${ }^{12}$ La seguridad humana surge como un concepto propuesto en 1993 por el Programa de Naciones Unidas para el Desarrollo cuya significación responde a dos factores: la percepción de inseguridad ${ }^{13}$ y el Estado de satisfacción de necesidades. ${ }^{14}$

El enfoque actual de la seguridad se relaciona con el desarrollo humano como una nueva dimensión de la seguridad humana. Ésta busca situar al ser humano como eje del desarrollo y tiene una correlación con factores como los derechos humanos, la salud, el medioambiente, la democracia, la seguridad alimentaria. Asimismo, "incluye el acceso a los elementos básicos para la vida; la protección del individuo frente al crimen y al terrorismo; las enfermedades sociales; la corrupción política; las migraciones masivas; el desarrollo político, económico y democrático; la sustentabilidad ambiental y los esfuerzos para controlar y reducir la contaminación". ${ }^{15}$

De esta manera, la seguridad humana se integra al tradicional concepto de seguridad, con una visión amplia que busca garantizar a las personas una vida segura y digna, libre de necesidades y temores. En este contexto, la igualdad de oportunidades ocupa un lugar importante para el desarrollo máximo de las capacidades humanas. Así, el bienestar de las personas se sitúa como el principal objetivo de la seguridad humana, aunado a los tratamientos asociados con la fuerza pública, con el mantenimiento de la ley y el orden público, así como de la erradicación de la violencia y la inseguridad.

La seguridad ciudadana constituye una de las piedras angulares del respeto a los derechos humanos enfocados, de la misma manera, en la persona humana. Este tipo de seguridad se suele estudiar como sinónimo de la seguridad

\footnotetext{
12 Valero, Ricardo, "La seguridad colectiva en América Latina", en Manuel Becerra Ramírez y Nuria González Martín (coords.), Estado de Derecho Internacional, México, Universidad Nacional Autónoma de México, 2012.

${ }^{13}$ De acuerdo con datos del Inegi, 76.8\% de la población de 18 años y más estima que vivir en su ciudad es inseguro. En este sentido, las ciudades con mayor percepción de inseguridad se encuentran la Región Oriente de la Ciudad de México, Coatzacoalcos, Fresnillo, Región Norte de la Ciudad de México, Chilpancingo de los Bravo y Cancún. Además, $81.3 \%$ de la población mexicana siente inseguridad en los cajeros automáticos situados en la vía pública, 74.3\% en el transporte público, 68.7\% en las calles que habitualmente usa y $68.1 \%$ en el banco. INSTITUTO NACIONAL DE Estadistica y Geografia, "Encuesta Nacional de Seguridad Pública Urbana 2018", Inegi. [Consulta: junio, 2018]. Disponible en: http://www.beta.inegi.org.mx/app/saladeprensa/noticia.html?id=4134

${ }^{14}$ Valencia Ramirez, Verónica Guadalupe, "La seguridad pública como derecho humano", en Certamen de ensayo sobre derechos humanos, Toluca, Comisión de Derechos Humanos del Estado de México - Legislatura del Estado de México, 2002.

${ }^{15}$ Valero, Ricardo, "La seguridad colectiva en América Latina", en Manuel Becerra Ramírez y Nuria González Martín (coords.), Estado de Derecho Internacional, México, Universidad Nacional Autónoma de México, 2012, p. 373.
} 
pública, aunque en estricto sentido conservan diferencias contundentes, sobre todo en cuanto a la persona como objeto o fin de su tutela.

La seguridad pública se centra en el orden político, a través de acciones que tienden a garantizar la paz pública, por medio de la prevención y represión de los delitos y las faltas contra el orden público. Por su parte, la seguridad ciudadana se sitúa como objeto central de la protección estatal para la persona humana, así como para un ambiente armónico y pacífico. ${ }^{16}$

La seguridad ciudadana supone una situación social en donde todas las personas, como miembros de la sociedad, gozan libremente de sus derechos y libertades fundamentales. Por otra parte, este tipo de seguridad implica la capacidad del Estado para garantizar el pleno ejercicio de estos derechos y para responder ante las afectaciones que se causen a los mismos. ${ }^{17}$ Bajo este contexto, la seguridad ciudadana se puede entender como:

la situación institucional y social en la cual las personas pueden gozar plenamente y ejercer integralmente sus libertades y derechos [...] comprende el conjunto de las acciones institucionales y sociales tendientes a resguardar y garantizar plena y efectivamente las libertades y derechos de las personas, a través de la prevención, conjuración e investigación de los delitos, las infracciones y los hechos vulneratorios del orden público. ${ }^{18}$

Por su parte, la Comisión Interamericana de Derechos Humanos ha referido que la seguridad ciudadana es:

aquella situación donde las personas pueden vivir libres de las amenazas generadas por la violencia y el delito, a la vez que el Estado tiene

\footnotetext{
${ }^{16}$ De acuerdo con el Informe sobre Seguridad Ciudadana y Derechos Humanos, "la expresión seguridad ciudadana surgió, fundamentalmente, como un concepto en América Latina en el curso de las transiciones a la democracia, como medio para diferenciar la naturaleza de la seguridad en democracia frente a la seguridad en los regímenes autoritarios. En estos últimos, el concepto de seguridad está asociado a los conceptos de 'seguridad nacional' [...] En los regímenes democráticos [...] se asocia a la 'seguridad ciudadana' y se utiliza en referencia a la seguridad primordial de las personas y grupos sociales". Comisión Interamericana de Derechos Humanos, Informe sobre seguridad ciudadana y derechos humanos, Comisión Interamericana de Derechos Humanos. [Consulta: octubre, 2017]. Disponible en: http://www.cidh.org/pdf\%20files/SEGURIDAD\%20CIUDADANA\%202009\%20ESP.pdf

17 Programa de las Naciones Unidas para el Desarrollo, Desarrollo humano en Chile. Las paradojas de la modernización, Santiago de Chile, PNUD, 1998.

${ }^{18}$ Álvarez, Aleandro, "El estado de la seguridad en América Latina: una aproximación a la evaluación situacional e institucional de la seguridad ciudadana en la región", Programa de las Naciones Unidas para el Desarrollo - LAC SURF, 2006. [Consulta: octubre, 2017]. Disponible en: https://es.scribd.com/document/36299474/EL-ESTADO-DE-LA-SEGURIDAD-EN-AMERICA-LATINA
} 
las capacidades necesarias para garantizar y proteger los derechos humanos directamente comprometidos frente a las mismas. En la práctica, la seguridad ciudadana, desde un enfoque de los derechos humanos, es una condición donde las personas viven libres de la violencia practicada por actores estatales o no estatales.

La garantía de la seguridad ciudadana exige una buena calidad de vida para la ciudadanía. "La pobreza y la falta de oportunidades, el desempleo, el hambre, el deterioro ambiental, la represión política, la violencia, la criminalidad y la drogadicción pueden constituir amenazas a la seguridad ciudadana." ${ }^{19}$ El aseguramiento de la integridad física y de los bienes de las personas ocupa un lugar relevante en el cumplimiento de esta obligación. La seguridad ciudadana busca evitar cualquier temor o acción violenta que afecte el libre ejercicio de los derechos y libertades fundamentales tendientes al progreso y el desarrollo humano.

Los actuales índices de violencia ${ }^{20}$ han posicionado a la seguridad ciudadana como una de las principales demandas sociales en los países de América Latina. El crimen organizado; ${ }^{21}$ la presencia de un alto número de armas de fuego en manos de particulares; el abuso de sustancias estupefacientes; la violencia contra los grupos en situación de vulnerabilidad y los conflictos que involucran a movimientos sociales y comunitarios son sólo algunas de las formas de violencia que incrementan la inseguridad.

La construcción de una política pública en materia de seguridad ciudadana exige el cumplimiento de ciertos estándares que a la vez conformen los límites de la actividad estatal. Estas directrices encuentran su fundamento en el derecho internacional de los derechos humanos. Los Estados deben cumplirlos para garantizar los derechos más vulnerados frente a los contextos críticos de violencia e inseguridad. Para poder alcanzar este objetivo, se requiere capacidad

\footnotetext{
19 Instituto Latinoamericano y del Caribe de Planificación Económica y Social y Ministerio de Planificación y Cooperación de la RePública de CHILE, Guía para la identificación, preparación y evaluación de proyectos de seguridad pública, Santiago de Chile, Ilpes - Mideplan, 1998, p. 5.

${ }^{20}$ Los homicidios femeninos en América Latina "ascienden a 4.3 por 100000 mujeres, cifra que es casi el doble que el promedio mundial de 2.3 victimas por 100000 mujeres". JAITMAN, LAURA, Los costos del crimen y de la violencia: nueva evidencia y hallazgos en América Latina y el Caribe, Washington, D. C., Banco Interamericano de Desarrollo, 2017, p. 98, [Consulta: noviembre, 2017]. Disponible en: https://publications.iadb.org/bitstream/handle/11319/8133/Los-costos-del-crimen-y-de-la-violencia-nueva-evidencia-y-hallazgos-en-America-Latina-y-el-Caribe.pdf?sequence=8 ${ }^{21}$ Según la organización Semáforo Delictivo, en el primer trimestre de 2018, las ejecuciones del crimen organizado aumentaron 35\%, pues en marzo se registraron 2346 homicidios, de los cuales 75\% corresponden a ejecuciones por parte del crimen organizado. GandariA, Manrioue, "Ejecuciones del crimen organizado aumentan 35\% en primer trimestre de 2018: Semáforo Delictivo", El Sol de Toluca, 24 de abril, 2018. [Consultada: junio, 2018]. Disponible en: https://www.elsoldemexico.com.mx/mexico/justicia/ejecuciones-del-crimen-organizado-aumentan-35-en-primer-trimestre-de-2018-semaforo-delictivo-1637991.html
} 
institucional por parte de las autoridades legítimas para diseñar, implementar y evaluar estas políticas de prevención y control de la violencia. Esto es, en palabras de Alejandro Álvarez, una gobernabilidad democrática de la seguridad ciudadana. ${ }^{22}$

Por lo anterior, la seguridad se puede analizar a partir de diversas perspectivas, así como factores, que influyen positiva o negativamente en cada caso concreto. Dentro de esta gama de vertientes, el presente trabajo se centra en el análisis de la función policial, a partir de la perspectiva de los derechos humanos, entendidos como el piso común en el que se debe basar dicha función pública.

\section{La función policial}

La función policial ocupa un lugar primordial en materia de seguridad ciudadana. Por ello, la legitimidad y eficacia de las actuaciones de estos agentes estatales son fundamentales para promover la seguridad, la justica y los derechos humanos en las sociedades democráticas. La cuestión policial justifica su trascendencia actual, pues, además de ejercer una función indispensable de la administración del Estado, es un instrumento de intervención social que tiene un efecto en las principales formas de relación entre el Estado y la sociedad. ${ }^{23}$

Desde esta perspectiva, la investigación que se expone analiza el ejercicio y la normatividad de la función policial, para determinar si dicha función pública cumple con los estándares mínimos que exigen los criterios en materia de derechos humanos o, en su defecto, para destacar los desafíos que en la actualidad se presentan.

La función pública atribuida a los policías tiene como principales objetivos mantener la seguridad y el orden en lugares públicos; hacer respetar las leyes y proteger a los ciudadanos y sus bienes de peligros y actos delictivos. En México, la función policial se divide en tres: ${ }^{24}$ municipal, estatal y federal.

\footnotetext{
22 Álvarez, Alejandro, "El estado de la seguridad en América Latina: una aproximación a la evaluación situacional e institucional de la seguridad ciudadana en la región", Programa de las Naciones Unidas para el Desarrollo - LAC SURF, 2006. [Consulta: octubre, 2017]. Disponible en: https://es.scribd.com/document/36299474/EL-ESTADO-DE-LA-SEGURIDAD-EN-AMERICA-LATINA

${ }^{23}$ Cfr. Gil MÁrouez, Tomas, El sistema de seguridad pública en la constitución española de 1978, Memoria de la tesis doctoral, Universitat A.Oliba. [Consulta: octubre, 2017]. Disponible en: http://www.tdx.cat/bitstream/handle/10803/9364/Ttgm.pdf?sequence $=1$

${ }^{24}$ De acuerdo con la Encuesta Nacional de Ocupación y Empleo (ENOE), al primer trimestre de 2017 se reportaron 331000 policías y agentes de tránsito en México, de éstos, 82 de cada 100 son hombres. Su escolaridad en promedio es de 11 años, es decir, el equivalente a tener dos años dentro del nivel medio superior de educación. Laboran 65.4 horas a la semana y ganan 31.3 pesos por hora trabajada. Insituto Nacional DE Estadistica y GEografia, "Estadística a propósito de los policias y agentes de tránsito", Inegi. [Consulta: noviembre, 2017]. Disponible en: http://www.inegi.org.mx/saladeprensa/aproposito/2017/agentes2017_Nal.pdf
} 
Las dos primeras, es decir, las policías municipal y estatal, sólo tienen carácter preventivo. Mientras, la policía federal tiene funciones mucho más amplias, como salvaguardar la vida, la integridad, la seguridad y los derechos de las personas; prevenir delitos; preservar las libertades, el orden y la paz públicos, y, adicionalmente, investigar y perseguir a los presuntos responsables de delitos de índole federal.

La función policial es un término cuya significación está impulsada por toda una serie de variables que incluyen políticas públicas, factores culturales y económicos, así como la infraestructura social y gubernamental de los Estados. Los enfoques de esta función varían en casi todos los casos, desde una policía con alto nivel de control, hasta lo que se ha denominado como policía por consentimiento. "El primer tipo suele ser altamente centralizado, preferentemente reactivo y de tipo militarista. El segundo puede ser centralizado, pero interpreta la actividad policial más bien como una respuesta a las necesidades de la comunidad local en cuanto a la detección y resolución de los problemas que requieren intervención policial." 25

El cumplimiento de esta importante responsabilidad supone un elemento positivo para la satisfacción de las necesidades y para la tutela de las libertades y derechos fundamentales de la sociedad. Pero, como es natural, el ejercicio de estas facultades presenta simultáneamente la posibilidad de graves abusos 0 trasgresiones a los derechos. Es precisamente en este supuesto donde los derechos humanos deben reubicarse en la cima de la función policial.

La erradicación de la corrupción, el abuso del poder, el uso excesivo de la fuerza pública, las detenciones ilegales y arbitrarias, así como los actos de tortura ${ }^{26}$ son algunos de los desafíos que plantea el ejercicio de la función policial en nuestros días. Para poder establecer líneas de acción que permitan combatir estas malas prácticas resulta indispensable analizar la función policial desde sus orígenes, así como desde el ámbito normativo que determina los límites legales con los que deben actuar los elementos de seguridad. Asimismo, se

\footnotetext{
${ }^{25}$ Oficina de las Naciones Unidas Contra la Droga y el Delito, Policía 2: integridad y responsabilidad de la policía. Manual de instrucciones para la evaluación de la justicia penal, Nueva York, Naciones Unidas, 2010, p. 1. [Consulta: octubre, 2017]. Disponible en: https://www.unodc.org/documents/justice-and-prison reform/crimeprevention/The_Integrity_and_Accountability_of_the_Police_Spanish.pdf

${ }^{26}$ Para un análisis más detallado de la tortura como desafío del Estado de derecho, así como de la situación específica que vive actualmente el Estado mexicano en materia de abuso de autoridad y actos de tortura, véase BernAL Ballesteros, María José, "La tortura en México como desafío del Estado de derecho en el siglo xxI", en Enrique Cruz Martínez y Mario Cruz Martínez (coords.), Perspectiva de los desafíos del Estado de derecho en el México del siglo xxı", México, Tirant lo Blanch, 2017, pp. 221-242.
} 
debe advertir que los aspectos culturales, económicos y políticos de los Estados constituyen variantes por considerar en cada caso concreto.

Los orígenes etimológicos de la palabra policía devienen del griego polis, que significa ciudad o Estado y, más concretamente, del vocablo Politeia, que se refería a lo relativo a la Constitución de la ciudad o del ordenamiento jurídico del Estado. Posteriormente, se trasformó al término en latín politia, para finalmente convertirse en el término que actualmente conocemos como policía. ${ }^{27}$

En el Estado absolutista, el poder se encontraba monopolizado, a través de sus instituciones y se ejercía, incluso, de manera ilegal o arbitraria. La función policial -es decir, el orden y la fuerza públicos-, en aquel momento, se concentraba en las fuerzas militares, lo cual generaba una confusión entre la función militar y la función policial. Más tarde, con la Revolución francesa, el actuar del Estado quedó limitado al ministerio de la ley, para poner fin al despotismo y garantizar los derechos fundamentales, a través de su reconocimiento normativo.

La Declaración de los Derechos del Hombre y del Ciudadano fue el documento de mayor importancia en aquel momento, dado su contenido protector de derechos y libertades fundamentales. Éste estableció en su artículo 12 que: "la garantía de los derechos del hombre y del ciudadano necesita de una fuerza pública. Esta fuerza se instituye, por tanto, para beneficio de todos y no para la utilidad de aquellos que la tienen a su cargo". ${ }^{28}$ A través de este pronunciamiento, por primera vez, la fuerza pública como mecanismo de coerción y orden social, quedó claramente encaminada hacia el bien común y el aseguramiento de la dignidad de las personas.

Es posible ubicar tantos modelos policiales como países, dado que el desempeño de la seguridad pública se vincula directamente con la historia y cultura de cada sociedad. Sin embargo, resalta la similitud entre las mismas. Dentro del contexto histórico, han destacado dos grandes modelos: el continental o francés y el anglosajón o inglés. El modelo continental o de policía del Estado se caracterizó por ser un sistema policial constituido desde el poder hacia el pueblo, es 260 decir, un poder centralizado, con estructura organizativa militarizada, alejado de la sociedad y con un mayor uso de la fuerza física. Por su parte, el modelo inglés fue un modelo descentralizado, legitimado y cercano a la sociedad, al cual

\footnotetext{
27 Delgado Mallarino, Victor Alberto, "Policía, derechos humanos y libertades individuales", Revista del Instituto Interamericano de Derechos Humanos, núm. 17, p. 87.

${ }^{28}$ Asamblea Nacional Francesa, "Declaración de los Derechos del Hombre", Conseil Constitutionnel. [Consulta: octubre, 2017]. Disponible en: http://www.conseil-constitutionnel.fr/conseilconstitutionnel/root/bank_mm/espagnol/ es_ddhc.pdf
} 
se le atribuyó un menor empleo de la fuerza física y de la coacción, a cambio de un mayor enfoque en la función de prevención. ${ }^{29}$

Las diferentes concepciones sobre la policía se deben a que este término se encuentra estrechamente vinculado con las características sociopolíticas y culturales de cada sociedad. A pesar de ello, podemos encontrar definiciones que, con sus respectivas adecuaciones, se pueden utilizar para el presente estudio.

De acuerdo con el Diccionario de la Lengua Española, la palabra policía refiere a un "cuerpo encargado de velar por el mantenimiento del orden público y la seguridad de los ciudadanos, a las órdenes de las autoridades políticas”. Por su parte, Sotelo define a la policía como "un organismo civil armado, que tiene a su cargo velar porque se cumplan la Constitución, las leyes y los reglamentos que de ella emanan, protegiendo la vida humana y la propiedad, para hacer más segura, agradable y cómoda la convivencia social". ${ }^{30}$

Delgado Mallarino ha señalado que existen diversas acepciones del término policía, dentro de las cuales podemos destacar: $a$ ) la policía como poder; $b$ ) la policía como función; c) la policía como servicio; d) la policía como norma, y e) la policía como institución. ${ }^{31}$

La policía como poder se refiere a la facultad que tiene el Estado a través de sus agentes. Normalmente se le reconoce en los textos constitucionales la capacidad de limitar las libertades y derechos, cuando esto implique el aseguramiento de la comunidad. La policía como función, dice el autor, se refiere a la actividad permanente y constante, tendiente a preservar la armonía y el orden social. La policía como servicio es una obligación a cargo del Estado, cuyo fin es satisfacer las necesidades de seguridad y mantenimiento de la paz y el orden público de una nación. La policía como norma es el conjunto de prerrogativas que facultan al Estado, a través de sus agentes, para llevar a cabo acciones con el fin de impedir que se violen las normas en perjuicio de la comunidad social. Finalmente, este autor entiende la policía como institución al ser un cuerpo civil, de carácter permanente y que se encuentra a cargo del Estado, con principios, objetivos, políticas e ideologías específicas.

Desde sus orígenes, el Estado se ha relacionado con el derecho, no obstan261 te, éste no siempre funcionó como un límite a la actuación estatal. El Estado de derecho, según Márquez Rábago, logró su consolidación con el triunfo del

\footnotetext{
${ }^{29} \mathrm{Cfr}$. Jar Consuelo, Gonzalo, "El papel de la policía en una sociedad democrática", Revista española de investigaciones sociales, núm. 85, pp. 199-220.

30 Sotelo Regil, LuIS, Policía profesional, México, Limusa, 2000, p. 17.

${ }_{31}$ Delgado Malarino, Victor Alberto, "Policía, derechos humanos y libertades individuales", Revista del Instituto Interamericano de Derechos Humanos, núm. 17, pp. 87-110.
} 
liberalismo francés, es decir, con el agotamiento del absolutismo. Esto dio lugar a la primera república federal (en Estados Unidos de América, en 1787) y, posteriormente, a la Carta de los Derechos del Hombre y del Ciudadano. ${ }^{32}$

En cualquier Estado de derecho existen mínimos que deben ser atendidos en cuanto a la estructura y funcionamiento de los gobiernos y del poder que aquel detenta. Uno de los principales elementos que distinguen este tipo de Estado es que todas las actuaciones deben de estar regidas bajo el principio de legalidad. Pero, el hecho de que una sociedad se rija de acuerdo con sus leyes no le garantiza vivir en un verdadero Estado de derecho. Se trataría de un término más limitado, es decir, un Estado de legitimidad. Esta idea es precisamente la que encierra Ferrajoli cuando afirma:

Para que una norma sea válida además de vigente, no basta que haya emanado de las formas predispuestas para su producción, sino que también es necesario que sus contenidos sustanciales respeten los principios y los derechos fundamentales establecidos tanto en la Constitución como en los cuerpos normativos internacionales. Es así como a través de esta evolución jurídica se da un nuevo significado al constitucionalismo. ${ }^{33}$

El Estado de derecho va más allá de un cuerpo normativo, conlleva una relación estrecha entre derecho, democracia y derechos humanos. ${ }^{34} \mathrm{Su}$ cumplimiento exige el imperio de la ley, pero, además, que haya diferenciación o separación en la actuación de los poderes. Asimismo, es necesario que se dé la fiscalización de la administración, es decir, un control jurídico y un control político, y que se cumpla con el irrestricto respeto de los derechos y libertades fundamentales. Así, en palabras de Elías Díaz, el Estado de derecho puede ser entendido como "aquel en que esas regulaciones normativas se producen hoy desde la libre participación democrática, incorporando eficazmente los derechos fundamentales". ${ }^{35}$

\footnotetext{
${ }^{32}$ Márouez Rábago, Sergio, "El Estado de derecho en México", en David Cienfuegos Salgado y Luis Gerardo Rodríguez Lozano (coords.), Estado, derecho y democracia en el momento actual. Contexto y crisis de las instituciones contemporáneas, Monterrey, Fondo editorial jurídico, 2008, pp. 211-230. [Consulta: noviembre, 2017]. Disponible en: https://archivos.juridicas.unam.mx/www/bjv/libros/6/2990/13.pdf

${ }^{33}$ FerRAJol, Luigl, Derechos y garantías: La ley del más débil, Madrid, Trotta, 2006, p. 43.

${ }^{34}$ Cfr. Bernal Ballesteros, María José, Olvera Garcia, Jorge y Uribe Arzate, Enrioue, "Los derechos humanos en el contexto del Estado constitucional", Dignitas, núm. 21, p. 43.

${ }^{35}$ Diaz, EliAs, "Estado de derecho y legitimidad democrática", en Miguel Carbonell, Wistano Orozco y Rodolfo Vázquez (coords.), Estado de derecho: concepto, fundamentos y democratización en América Latina, México, Siglo XXI, 2002, pp. 70-71.
} 
Dicho de otra manera, los derechos humanos son la razón de ser del Estado de derecho, y la democracia, por su parte, sólo puede existir en un Estado de derecho pleno y consistente. La función policial se analizará desde esta perspectiva, pues al ser una responsabilidad estatal que atiende necesidades de primer orden de la ciudadanía debe, indiscutiblemente, implementarse a través de políticas sustentadas en el respeto y tutela de los derechos humanos que permitan garantizar la paz social.

Entonces, la actuación policial aparece como una función estatal tendente a garantizar el orden público $\mathrm{y}$, consecuentemente, la efectividad del derecho humano para la seguridad ciudadana. El Estado, a través de la legalidad y legitimidad que rige sus actos, es quien ostenta el monopolio de la fuerza. Dicha atribución se encuentra conferida en la policía como institución, encargada de velar por el orden y la seguridad públicos, para lo cual cuenta con facultades amplias de prevención, control y coerción.

De manera genérica y no limitativa, se puede decir que la función policial implica que los agentes de seguridad, dentro del ámbito de sus respectivas competencias deben proteger a la integridad de las personas y sus bienes; mantener la tranquilidad y el orden público; salvaguardar el ejercicio de las libertades públicas; prevenir los delitos y faltas administrativas, $\mathrm{y}$, en los casos de la policía judicial, actuar como agente auxiliar de la procuración con apego a la ley, la ética y el respeto a los derechos humanos. ${ }^{36}$

Respecto a la policía y el uso de la fuerza pública, cabe decir que los derechos humanos constituyen, o deberían constituir, el principal límite del uso de la fuerza pública. Independientemente del contexto social y de los motivos por los cuales los agentes estatales deban implementar esta fuerza, la premisa de la protección de los derechos fundamentales debe regir su actuación en todo momento.

El empleo de la fuerza pública se configura desde dos vertientes: la preventiva y la reactiva. La primera atiende a la prevención general de la conducta ilícita -contraria a la norma y al orden social- y evita, al mismo tiempo, las acciones de contención y control de los agentes de seguridad. Por su parte, la función reactiva del uso de la fuerza busca incidir en la conducta ya desplegada que violenta la norma y pone en riesgo su propia seguridad, la de terceros y la de la propia policía. Por tanto, en este supuesto, es necesario emplear el uso de la fuerza pública para restablecer el orden y la convivencia armónica de la sociedad. ${ }^{37}$

\footnotetext{
${ }^{36}$ Ramirez Ramirez, EFrén, Los derechos humanos en la formación de la policía judicial. Manual de capacitación, México, Procuraduría General de Justicia del Distrito Federal e Instituto Nacional de Ciencias Penales, 2005, pp. 135-137. ${ }^{37}$ Robledo Madrid, Wilfrido, "Uso de la fuerza pública, ¿Cómo y cuándo utilizarla?", en El uso de la fuerza pública en un estado democrático de Derecho. Memoria del Congreso internacional, México, Instituto Nacional de Ciencias
} 
La facultad estatal para emplear la fuerza pública atiende a su responsabilidad de garantizar el orden y la paz públicos, a través de la resolución de conflictos individuales o colectivos. Sin embargo, en muchas ocasiones se ha abusado de esta facultad, causando graves afectaciones a la integridad de las personas. La fuerza pública debe emplearse en congruencia con los principios de necesidad y de proporcionalidad. En este sentido, la Corte Interamericana de Derechos Humanos ha reiterado:

Conforme a las pautas internacionales que se han elaborado referentes al uso de la fuerza por parte de los agentes de seguridad pública para cumplir su función, esa actividad debe ser necesaria y proporcional a las necesidades de la situación y al objetivo que se trata de alcanzar. Asimismo, la adecuación de los procedimientos de los agentes estatales de seguridad a los parámetros internacionales significa que el empleo de la fuerza debe ser tanto necesario como proporcional a la situación, es decir, que debe ser ejercido con moderación y con proporción al objetivo legítimo que se persiga.

Antes de recurrir al empleo de la fuerza física, medios de coacción o uso de armas de fuego, es indispensable que los policías utilicen medios no violentos para enfrentar la situación de riesgo o que atente contra la seguridad ciudadana. Para ello, es ineludible que se actualicen dos aspectos. Primero, debe existir una normatividad estatal específica para el uso de la fuerza pública, en la cual se incluya una perspectiva de derechos humanos. Segundo, los cuerpos de seguridad deben estar totalmente capacitados en la materia, es decir, tener una cultura de legalidad y de respeto a los derechos humanos.

Aun cuando México no tiene una ley general sobre el uso de la fuerza pública, existen diversas disposiciones en los estándares normativos a los cuales se deben sujetar las actuaciones de los agentes estatales de seguridad. El artículo 21 de la Constitución Política de los Estados Unidos Mexicanos alude a que la seguridad pública es una función a cargo de la federación, las entidades federativas y los municipios, en el ámbito de sus respectivas competencias. Por ello, las instituciones de seguridad pública deben regirse por los principios de legalidad, objetividad, eficiencia, profesionalismo, honradez y respeto a los derechos humanos. ${ }^{38}$ 
Por su parte, el Protocolo de Actuación de la Policía Federal sobre el Uso de la Fuerza establece los parámetros y condiciones mínimas que diferencian y definen el uso, las técnicas, los niveles y los principios con los cuales los policías federales deben ejercer la fuerza. Si bien es cierto que dicho protocolo no es aplicable a todos los elementos de seguridad, no debe pasar desapercibido que constituye un elemento normativo importante por cuanto hace a su contenido y a los criterios nacionales e internacionales que alude. ${ }^{39}$

En el ámbito internacional, el Código de Conducta para Funcionarios Encargados de Hacer Cumplir la Ley ${ }^{40}$ establece que, en el desempeño de sus tareas, protegerán la dignidad humana, manteniendo y defendiendo los derechos humanos. Establece que el uso de la fuerza debe ser excepcional, en la medida en que sea necesaria para la prevención de un delito y no podrá usarse de manera que exceda estos límites. Asimismo, en su artículo tercero, señala que dichos funcionarios sólo podrán usar la fuerza cuando sea estrictamente necesario y en la medida que lo requiera el desempeño de sus tareas.

Por otro lado, los Principios Básicos sobre el Empleo de la Fuerza y de Armas de Fuego por los Funcionarios Encargados de Hacer Cumplir la Ley, ${ }^{41}$ conocidos como Principios de la Habana, señalan en el numeral 4 que los funcionarios encargados de hacer cumplir la ley, en el desempeño de sus funciones, utilizarán en la medida de lo posible medios no violentos, antes de recurrir al empleo de la fuerza y de armas de fuego. Según este texto, pueden utilizar estos últimos solamente cuando otros medios resulten ineficaces o no garanticen de ninguna manera el logro del resultado previsto. Asimismo, su numeral 19

\footnotetext{
nos, asi como por la Comisión de Derechos Humanos del Estado de México) y que la Legislatura haga las adecuaciones. En dichas acciones de inconstitucionalidad, se solicitó la invalidez de algunas de sus disposiciones, al referir que la ley publicada en el Estado de México no cumplia con los estándares y criterios internacionales y nacionales en materia de uso de la fuerza pública. En 2017, la Suprema Corte de Justicia de la Nación resolvió la acción de inconstitucionalidad 25/2016 y sus acumuladas $27 / 2016$ y 28/2016. Actualmente, queda pendiente la publicación de dicha ley. Cfr. "Acción de Inconstitucionalidad 25/2016 y sus acumuladas 27/2016 y 28/2016", Suprema Corte de Justicia de la Nación. [Consulta: noviembre, 2017]. Disponible en: https://www.scjn.gob.mx/sites/default/files/proyectos_resolucion_scjn/documento/2017-02/ACCION\%20INCONS\%20\%2027\%20Y\%2028\%20ACUMULADAS\%20 DEFINITIVA\%20A\%20PUBLICAR_0.pdf

${ }^{39} \mathrm{Cfr}$. Acuerdo 04/2012 del Secretario de Seguridad Pública, por el que se emiten los lineamientos generales para la regulación del uso de la fuerza pública por las instituciones policiales de los órganos desconcentrados en la Secretaría de Seguridad Pública, 23 de abril 2012, Diario Oficial de la Federación.

${ }^{40}$ Organización de las Naciones Unidas, "Resolución 34/169", Organización de las Naciones Unidas, 17 de diciembre, 1979. [Consulta: octubre, 2017]. Disponible en: https://www.ohchr.org/SP/Professionallnterest/Pages/LawEnforcementOfficials.aspx

${ }^{41}$ Organización de las Naciones Unidas, "Principios Básicos sobre el Empleo de la Fuerza y de Armas de Fuego por los Funcionarios Encargados de Hacer Cumplir la Ley", Organización de las Naciones Unidas, La Habana, Cuba, 7 de septiembre, 1990. [Consulta: noviembre, 2017]. Disponible en: http://www.ohchr.org/SP/Professionallnterest/Pages/ UseOfForceAndFirearms.aspx
} 
indica que los gobiernos y los organismos encargados de hacer cumplir la ley procurarán que todos los funcionarios de este orden reciban capacitación en el empleo de la fuerza y sean examinados de conformidad con normas de evaluación adecuadas. Los funcionarios que deban portar armas de fuego estarán autorizados para hacerlo sólo tras haber finalizado la capacitación especializada en su empleo.

De manera particular, la Corte Interamericana de Derechos Humanos, en el Caso Zambrano Vélez y otros vs. Ecuador, consideró la excepcionalidad, necesidad, proporcionalidad y humanidad en el uso de la fuerza, en el sentido siguiente:

El uso de la fuerza debe estar limitado por los principios de proporcionalidad, necesidad y humanidad. La fuerza excesiva o desproporcionada por parte de los funcionarios encargados de hacer cumplir la ley que da lugar a la pérdida de la vida puede por tanto equivaler a la privación arbitraria de la vida. El principio de necesidad justifica sólo las medidas de violencia militar no prohibidas por el derecho internacional, que son relevantes y proporcionadas para garantizar el pronto sometimiento del enemigo con el menor gasto posible de recursos humanos y económicos. El principio de humanidad contempla y limita intrínsecamente el principio de necesidad, al prohibir las medidas de violencia que no son necesarias (es decir, relevantes y proporcionadas) para el logro de una ventaja militar definitiva. En situaciones de paz, los agentes del Estado deben distinguir entre las personas que, por sus acciones, constituyen una amenaza inminente de muerte o lesión grave y aquellas personas que no presentan esa amenaza, y usar la fuerza sólo contra las primeras. ${ }^{42}$

Recapitulando, tanto la Constitución Política de los Estados Unidos Mexicanos como los instrumentos internacionales reconocen que el Estado tiene la obligación de garantizar las libertades y derechos de su población, preservar el orden público y que el uso de la fuerza pública por parte de los encargados de hacer cumplir la ley, debe ser excepcional, legal, racional, proporcional, congruente, oportuna y con irrestricto respeto a los derechos humanos. ${ }^{43}$

\footnotetext{
${ }^{42}$ Corte IDH, Caso Zambrano Vélez y otros vs. Ecuador. Fondo, Reparaciones y Costas, sentencia del 4 de julio de 2007, párrafo 85.

${ }^{43}$ Para el logro de lo descrito, es necesaria la existencia de ordenamientos legales, reglamentarios y protocolarios que detallen y den precisión del ejercicio del acto de policía en relación con el uso de fuerza pública y uso de armas de fuego, como lo dispone la Tesis Aislada del Pleno de la Suprema Corte de Justicia de la Nación: seguridad pública. No basta la previsión de principios constitucionales que rijan la fuerza pública por parte de los cuerpos policiacos para normar
} 
En concordancia, los cuerpos de seguridad policial deberán tener en cuenta estos parámetros para ejercer sus funciones públicas. Es decir, la fuerza no debe emplearse de acuerdo con la voluntad de cada elemento de seguridad. Por el contrario, el uso de la fuerza se debe ajustar a los criterios internacionales y nacionales que determinan exclusivamente cuándo ha de emplearse la fuerza pública, y, en este supuesto, de qué forma. ${ }^{44}$ Así, la función policial debe atender siempre a los criterios normativos permitidos y a la preservación de la dignidad humana, aún en casos de extrema urgencia.

La función policial es un aspecto que se debe analizar, tomando en consideración distintos aspectos. Si bien existen cifras elevadas que evidencian el uso excesivo de la fuerza pública ${ }^{45}$ de los policías, también es necesario resaltar que las leyes y las instituciones con las cuales se cuentan requieren una exhausta revisión y reestructuración. La capacitación, la sensibilización, el cambio de cultura y la participación ciudadana juegan un papel importante para lograr el cambio social tan esperado. Así, el perfeccionamiento del Estado de derecho exige que los derechos humanos sean el eje trasversal de todas las actuaciones de la administración pública, incluyendo, por supuesto, la función policial.

\section{Los derechos humanos en la actuación policial}

Los derechos humanos se encuentran relacionados con la historia de la propia humanidad. Desde sus orígenes, el ser humano ha encabezado constantes luchas para acceder a mejores formas de vida, el respeto de su dignidad y de sus derechos y libertades fundamentales.

En el contexto actual, los derechos humanos coadyuvan a los elementos de gobernanza, incluyendo evidentemente a la administración pública. Pero, el trasfondo de estos derechos no sólo debe permear las actividades o responsabilidades estatales, pues la cultura de tutela de estos derechos constituye un elemento indispensable para el bien común y la satisfacción en las necesidades

su actividad, sino que su uso debe ser objeto de desarrollo normativo a nivel legal, reglamentario y protocolario, Tesis P. LXVII, Semanario Judicial de la Federación y su Gaceta, Novena Época, tomo XXXIII, enero de 2011, p. 65.

${ }^{44}$ La Comisión Nacional de los Derechos Humanos, el 26 de enero de 2006, emitió la Recomendación General número 12, sobre el uso ilegítimo de la fuerza y de las armas de fuego por los funcionarios y servidores públicos encargados de hacer cumplir la ley, dirigido al secretario de Seguridad Pública del Gobierno Federal, procuradores generales de la república y de Justicia Militar, gobernadores de las entidades federativas, jefe de Gobierno del Distrito Federal, procuradores generales de Justicia y responsables de Seguridad Pública de las entidades federativas y de los municipios.

${ }^{45}$ En 2017, la cNDH reportó que, entre los principales hechos violatorios contenidos en los 146 expedientes de queja, tuvieron más frecuencia la detención arbitraria (24), empleo arbitrario de la fuerza pública (7), ejercicio de violencia desproporcionada durante la detención (6) y daño derivado del empleo arbitrario de la fuerza pública (4). COMISIÓN NACIONAL DE los Derechos Humanos, Informe de Actividades del 1 de enero al 31 de diciembre de 2017, México, CNDH, 2018, p. 40. 
básicas en cualquier sociedad democrática de derecho. Visto desde este punto, está claro que los derechos humanos en engranaje con una normatividad adecuada y la ética pública tienen un impacto positivo y directo en la buena administración, entendida en su más amplio sentido.

Cuando nos referimos a los derechos humanos, debemos aludir a la dignidad, pues es el punto medular de su protección. Al respecto, Kant sostiene: "[Todo] tiene un precio o una dignidad. Lo que tiene un precio puede ser sustituido por otra cosa como equivalente; en cambio, lo que se halla por encima de todo precio y, por tanto, no admite equivalente, posee dignidad". ${ }^{46}$

Hablar de derechos humanos supone situar al ser humano como eje rector de cualquier actividad estatal o particular. Esto supone, además, enfocar las acciones a la protección y tutela de la dignidad humana, entendida como el valor mismo de la esencia de las personas. La definición de los derechos humanos es un concepto plural, existen tantas definiciones como autores, no obstante, los elementos que le distinguen del resto de los derechos son claros y contundentes. Se trata de un conjunto de prerrogativas, principios y valores atribuidos al ser humano y que son indispensables para el aseguramiento de su dignidad, así como para su pleno desarrollo.

En cuanto a sus características, los derechos humanos son universales, porque son patrimonio de todos los seres humanos; imprescriptibles, porque no se adquieren o se pierden con el paso del tiempo; inalienables, porque no pueden ser objeto de transferencia a otro sujeto; irrenunciables, porque no se puede hacer dejación voluntaria de ellos; e indivisibles, porque conforman una unidad, y no existe rango de jerarquía entre ellos. ${ }^{47}$

De acuerdo con Milagros Otero Parga, los derechos humanos pueden ser entendidos como "aquellos que reconocen o deben reconocer las leyes, y cuya titularidad corresponde al individuo en función de la dignidad que le otorga su naturaleza humana, y no por concesión de las normas positivas, sino con anterioridad e independencia de ellas". ${ }^{48}$

Por su parte, Mireille Roccatti Velázquez entiende que los derechos humanos son "aquellas facultades y prerrogativas inherentes a la persona humana, que le corresponden por su propia naturaleza, indispensables para asegurar su pleno desarrollo dentro de una sociedad organizada, mismos que deben ser

\footnotetext{
${ }^{46}$ Kant, Immanuel, Fundamentación de la metafísica de la costumbre, Madrid, Ediciones Encuentro, 2003, p. 74.

${ }^{47}$ Bernal Ballesteros, Maria José, Luces y sombras del ombudsman. Un estudio comparado entre México y España, Toluca, Comisión de Derechos Humanos del Estado de México - Universidade de Santiago de Compostela, 2015. ${ }^{48}$ Otero Parga, Milagros, Estudios de derechos humanos: Introducción a los derechos humanos, objeción de conciencia y ética judicial, Toluca, Comisión de Derechos Humanos del Estado de México, 2003, p. 17.
} 
reconocidos y respetados por el poder público o autoridad, debiendo ser garantizados por el orden jurídico positivo". ${ }^{49}$

Lo cierto es que, sin importar con cual comulguemos, todas las definiciones coinciden en que los derechos humanos son prerrogativas inherentes al ser humano, cuyo principal objetivo es salvaguardar la dignidad y su desarrollo integral. Además, suponen un conjunto de deberes y obligaciones, tanto para los Estados como para los individuos, y que el orden jurídico nacional e internacional deben reconocerlos y garantizarlos.

En este orden de ideas, la seguridad se debe entender como un derecho humano y un elemento sine qua non para la dignidad de las personas. Contrario sensu, la inseguridad supone una situación de riesgo en la gente y en sus bienes. Desde una perspectiva genérica, se trata de un derecho cuyo fin es asegurar el pleno y libre ejercicio del resto de los derechos fundamentales. Desde un enfoque más concreto, el derecho humano a la seguridad tutela la integridad de las personas, es decir, el conjunto de condiciones físicas, psíquicas y morales que le permiten al ser humano su existencia.

El derecho internacional de los derechos humanos, a través de sus diversos instrumentos normativos, alude a la obligación del Estado de garantizar la seguridad personal de los individuos. En términos del artículo 3 de la Declaración Universal de los Derechos Humanos: "Todo individuo tiene derecho a la vida, a la libertad y a la seguridad de su persona”. El artículo 1 de la Declaración Americana de los Derechos y Deberes del Hombre indica: "Todo ser humano tiene derecho a la vida, a la libertad y a la seguridad de su persona”. El artículo 7 de la Convención Americana sobre Derechos Humanos expresa: "Toda persona tiene el derecho a la libertad y a la seguridad personales". Por último, el artículo 9 del Pacto Internacional de Derechos Civiles y Políticos señala: "Todo individuo tiene derecho a la libertad y a la seguridad personales".

Como se puede advertir de los preceptos normativos referidos, el derecho a la seguridad se vincula directamente con otros derechos fundamentales. Así, se constituye como la antesala del goce y disfrute de derechos como la vida; la integridad personal; la libertad y la seguridad personales, la protección judicial y las garantías procesales; la privacidad; la honra; la libertad de expresión, de reunión y de asociación; el derecho a participar en los asuntos de interés público; derecho al disfrute pacífico de los bienes y, como consecuencia de todos los anteriores, el derecho a la dignidad de las personas.

\footnotetext{
${ }^{49}$ Roccatt, Mirellle, Los derechos humanos y la experiencia del ombudsman en México, Toluca, Comisión de Derechos Humanos del Estado de México, 1996, p. 19.
} 
Este artículo plantea una perspectiva clara en el ámbito de los derechos humanos. Se sostiene que la función policial, como actividad principal de la seguridad ciudadana -en cualquier escenario desde donde se quiera analizardebe tener como principio y fin la tutela y protección de los derechos humanos.

Contrario a lo aquí expuesto, se puede sostener que cualquier actividad del Estado que no cumpla con estos parámetros establecidos por el bloque de constitucionalidad en materia de derechos humanos, es decir, con los instrumentos internacionales y locales, estará dando un paso en la dirección incorrecta y al mismo tiempo, abrirá la brecha a actos de corrupción y de inseguridad que condenan el bienestar común y la vida pacífica de las sociedades.

La tutela de estos mínimos vitales constituye una obligación para todos los agentes estatales, es decir, de conformidad con el artículo primero constitucional, todas las autoridades o servidores públicos tienen, en el ámbito de sus respectivas atribuciones, el deber de proteger, respetar y garantizar los derechos humanos. ${ }^{50}$ En congruencia con dicha responsabilidad, los policías deberán cumplir con sus responsabilidades, incluso cuando ello suponga la limitación de ciertas libertades o derechos fundamentales, pero siempre asegurando la dignidad de las personas y de conformidad con los principios de necesidad y proporcionalidad.

Por tanto, los derechos humanos deben ser ese piso común que permita a todas las naciones avanzar en la dirección correcta hacia la paz y el desarrollo. Esto implica que tanto las autoridades como la sociedad nos sumemos y replanteemos las estrategias fallidas y divididas que se han llevado a cabo hasta el día de hoy.

Es necesario cerrar la brecha entre la normatividad y la realidad, que vivimos, así como diseñar estrategias conjuntas entre Gobierno y sociedad para fomentar un cambio de cultura en materia de derechos humanos. Asimismo, sensibilizarnos y entender tres aspectos indispensables: la función policial debe ser siempre respetuosa de la dignidad de las personas; los policías también tienen derechos humanos, y la seguridad sólo se alcanzará en medida que la ciudadanía respete y colabore con la función policial.

\section{La ética pública en la función policial}

\footnotetext{
${ }^{50}$ Para un estudio más detallado de las obligaciones generales y especificas en materia de derechos humanos, véase: Almanza Vega, Rigoberto Delfino, La reforma constitucional en materia de derechos humanos y los nuevos paradigmas del juicio de amparo, México, Porrúa, 2015.
} 
La palabra ética proviene del griego ethos, que significa costumbre, hábito; por su parte, costumbre, en latín, se deriva del término mos, moris; es decir, la ética por sí sola se relaciona con la costumbre y la moral. "El carácter moral expresa el modo de ser del hombre por medio del cual éste conoce, juzga y actúa justa o injustamente. Moral y ética hacen referencia por tanto al modo de ser de las personas." ${ }^{51}$

Pero, cuando ésta se pone en práctica en el servicio público, entonces se habla de la ética pública, entendida como aquella "que estudia y analiza el perfil, la formación y el comportamiento responsable y comprometido de las personas que se ocupan de los asuntos públicos, generando un cambio de actitud en ella al inculcarles valores de servicio público". ${ }^{52}$ Esta disciplina constituye un aspecto importante en el ejercicio de la función estatal porque establece los parámetros y las directrices que deben regir el actuar de cada servidor público y, por consiguiente, tiene un efecto directo en la actividad estatal y en la calidad de la Administración Pública.

La educación se fortalece a través de principios y valores que inician desde casa y que a través de la formación académica y profesional se van fortaleciendo. Los principios y valores generan conciencia y ésta, a su vez, permite generar responsabilidad ante nuestros comportamientos. Diego Bautista explica que "cuando no hay educación, ni principios ni valores en la mente de las personas, se da paso a la ignorancia [...] cultivo para los antivalores y las prácticas corruptas". ${ }^{53}$

En el mismo sentido, Betancourt Higareda sostiene que la formación ética y cívica dentro de una sociedad es un factor que influye positivamente en las sociedades, más allá de los factores socioeconómicos y culturales de cada Estado. Para sostener dicha afirmación hace referencia al contexto histórico, concretamente, a las civilizaciones griega y romana. Resalta que, desde aquella época, la ética y la jurisprudencia constituyeron el pilar fundamental de dichas sociedades, conscientes de la importancia que estas virtudes representaban para alcanzar el desarrollo, la prosperidad y la felicidad de sus respectivos pueblos. $^{54}$

\footnotetext{
${ }^{51}$ NAESSENS, HILDA, "Ética pública y transparencia", en 200 años de lberoamérica (1810-2010) Congreso internacional, Santiago de Compostela, Universidade de Santiago de Compostela, 2010, p. 2114.

52 NAESSENS, HILDA, "Ética pública y transparencia", en 200 años de Iberoamérica (1810-2010) Congreso internacional, Santiago de Compostela, Universidade de Santiago de Compostela, 2010, p. 2116.

${ }^{53}$ Diego BAutista, OscaR, "¿Cómo abordar la corrupción? Una vía para su solución a través de la ética pública" en Colección cuadernos para prevenir y controlar la corrupción, Tomo 4, México, Poder Legislativo del Estado de México, 2017, p. 24.

${ }^{54}$ Betancourt Higareda, Felipe Carlos, "Injusticia, desigualdades estructurales, y la construcción del Estado de derecho
} 
En palabras de Mario Cruz Martínez, "la ética pública es el espacio común de los ciudadanos, y más aún, es la forma en cómo todas y todos adoptan conductas que se vinculan justamente al cumplimiento de las reglas del funcionamiento de la comunidad política". ${ }^{55}$ Es, además, un importante mecanismo de control de la arbitrariedad en el uso del poder público. ${ }^{56}$

En la actualidad, la ética pública y los derechos humanos tienen una estrecha relación. El objetivo de ésta será que, con base en el cumplimento de determinados principios y valores, el servidor público realice su función de manera eficaz, pero, sobre todo, salvaguardando la dignidad, así como las libertades y derechos fundamentales de los gobernados. Más allá de contar con una normatividad administrativa que regule la función pública, se requiere de una nueva percepción de la realidad basada en la protección de los derechos humanos mediante el perfil adecuado de los servidores públicos.

Para coadyuvar con dicho objetivo, es importante que los agentes de seguridad y policías den cumplimiento a los principios con el debido interés superior de la niñez, el deber objetivo de cuidado de la perspectiva de género y de la legalidad. Además de que su actuar debe ajustarse a los valores de honradez, lealtad, imparcialidad, eficacia, interés público, respeto a los derechos humanos, igualdad y no discriminación, integridad, cooperación, liderazgo, trasparencia y rendición de cuentas.

Una de las principales consecuencias de la falta de ética y valores en el desempeño de la función pública es la corrupción, ${ }^{57}$ así como la ineficacia en

en México", en Enrique Cruz Martínez y Mario Cruz Martínez (coords.), Perspectiva de los desafíos del Estado de derecho en el México del siglo xxı", México, Tirant lo Blanch, 2017, pp. 43-64.

${ }^{55}$ Cruz Martinez, Mario, "Por una ética pública de la democracia en México: la cultura gubernamental de los derechos humanos", en Enrique Cruz Martínez (coord.), Por una nueva ética de lo público en México: Experiencias sobre el impacto de la corrupción en la eficiencia gubernamental, México, Fontamara - Universidad Autónoma del Estado de México, 2015, p. 185.

${ }^{56}$ En el caso del Estado mexicano, se han implementado algunas acciones con el objetivo de impactar favorablemente en la ética del sector público. Entre las estrategias implementadas, se encuentran: a) el código de ética de los servidores públicos del Gobierno Federal; las reglas de integridad para el ejercicio de la función pública y los lineamientos generales para propiciar la integridad de los servidores públicos y para implementar acciones permanentes que favorezcan su comportamiento ético, a través de los Comités de Ética y de Prevención de Conflictos de Interés; b) Código de conducta de los servidores públicos de la oficina de la Presidencia de la República; c) Comité de ética y de prevención de conflictos de interés de la Oficina de la Presidencia de la República; d) Código de ética para los diputados federales.

${ }^{57}$ De acuerdo con el Barómetro Global de la Corrupción, más de seis de cada diez personas que viven en América Latina y el Caribe suponen que el nivel de corrupción aumentó (62\%). Solamente uno de cada diez piensa que disminuyó, mientras la cuarta parte no percibe cambios. PRING, CoRALE, Las personas y la corrupción: América Latina y el Caribe. Barómetro Global de la Corrupción, Berlín, Transparency International, 2017, p. 9. [Consulta: noviembre de 2017]. Disponible en: http://www.libertadciudadana.org/archivos/BAROMETR02017/LAC\%20GCB\%20SP_9_0ctober_2017.pdf 
el ejercicio público. Estos elementos repercuten negativamente en la garantía del derecho a la buena administración. En este sentido, Bielsa refiere que la "corrupción en la función pública es la desnaturalización o desviación del regular ejercicio de la función pública, entendida ésta como la entera actividad del Estado, y no sólo en las funciones del Poder Ejecutivo como poder administrador, sino también en el ejercicio de las funciones legislativas, ejecutivas y judiciales". ${ }^{58}$

Las causas que originan el fenómeno de la corrupción son variadas y atienden a distintos factores y entornos sociales. La función policial es un factor recurrente que trastoca el tema de la seguridad ciudadana y, por consiguiente, afecta a toda la ciudadanía. La población de América Latina y el Caribe señala a la policía y a los representantes del Gobierno como los más corruptos. Cerca de la mitad de los ciudadanos (47\%) que habitan en la región consideran que las personas que trabajan en estas instituciones son todas, o casi todas, corruptas. ${ }^{59}$

Ante estas cifras, es claro que las instituciones policiales requieren de una restructuración de fondo, cuyo pilar sea, precisamente, los valores y la ética en el ejercicio público. Debido a que la corrupción evidencia una falta de respeto a los derechos humanos, resulta indispensable erradicar esta conducta, no sólo en los cuerpos de seguridad, sino en todos los servidores públicos. Para ello, es indispensable adquirir una cultura real de los derechos humanos, que los cuerpos de seguridad los hagan suyos, los conozcan y los entiendan. Esto con el fin de que, posteriormente, ejerzan sus funciones con una perspectiva de respeto a tales derechos fundamentales.

En los momentos de inseguridad e inestabilidad económica y social, como los que se viven actualmente, se debe contar con instituciones e instancias eficientes, "pero además, honestas, capaces de renovar un vínculo entre los actores gubernamentales, la acción pública, los resultados y las expectativas que los ciudadanos tienen de quienes los gobiernan" ${ }^{60}$ En medida que los cuerpos de policía lleven a cabo sus funciones apegadas a la normatividad y a la ética, se podrán obtener los resultados deseados en el ámbito de la seguridad ciudadana.

Debemos entender que la función de la policía se encuentra estrechamente vinculada con el respeto y la garantía de los derechos humanos. Es necesario

\footnotetext{
${ }^{58}$ Bielsa, Rafael Antonio y Brenna, Ramón Gerónimo, Reforma de la justicia y nuevas tecnologías, Buenos Aires, Ad Hoc, 1996, p. 276.

${ }^{59}$ Pring, CoRAle, Las personas y la corrupción: América Latina y el Caribe. Barómetro Global de la Corrupción, Berlín, Transparency International, 2017, p. 9. [Consulta: noviembre de 2017]. Disponible en: http://www.libertadciudadana. org/archivos/BAROMETR02017/LAC\%20GCB\%20SP_9_October_2017.pdf

${ }^{60}$ Cruz Martinez, Enrioue, Por una nueva ética de lo público en México: Experiencias sobre el impacto de la corrupción en la eficiencia gubernamental, México, Fontamara - Universidad Autónoma del Estado de México, 2015, p. 7.
} 
devolver a la sociedad la confianza en la fuerza pública instituida para su protección. Para tal efecto es indispensable asegurar la integridad y la eficacia del ejercicio de la función policial.

Bajo este contexto, me parece oportuno señalar que, ante los graves problemas que se plantean en las sociedades actuales, la ética pública se constituye como un remedio importante. Sobre todo, se debe enfocar en la prevención. Aunque no es lo único que una nación requiere para garantizar una buena administración y un verdadero Estado de derecho, esto se plantea como una directriz importante que nos permitirá estar más cerca de los objetivos planeados.

\section{Reflexiones finales}

Los derechos humanos deben constituirse como un límite y a la vez como un objetivo de las instituciones de seguridad pública. En las sociedades democráticas es evidente que los derechos humanos y la función policial tienen una relación estrecha, pues su finalidad es lograr el bienestar de la ciudadanía y garantizar su integridad y seguridad.

La actividad de la fuerza pública legítimamente orientada a la protección de la seguridad ciudadana ocupa un papel fundamental. Sin embargo, en la actualidad, el abuso de las autoridades policiales se ha constituido como un factor de riesgo para la seguridad de las personas.

Si bien es cierto que los cuerpos policiales, en ejercicio de sus funciones, cuando la ley lo estime necesario, pueden limitar el ejercicio de ciertos derechos y libertades, esto no puede, bajo ningún supuesto, justificar violaciones a derechos humanos. Las herramientas legales con las que cuentan los agentes estatales para defender la seguridad de la ciudadanía no pueden ser utilizadas para avasallar estos derechos.

La formación de la función policial desde la perspectiva de la ética pública y de los derechos humanos es un requisito sine qua non en los Estados democráticos de derecho. Son éstos quienes, a través de sus agentes, están obligados a garantizar el orden y la seguridad públicos. La participación de la ciudadanía en el alcance de este objetivo es un factor relevante, no obstante, estará sujeta al nivel de confianza que tengan en sus instituciones de seguridad, de ahí que resulte importante trabajar en dicha reestructuración institucional y funcional.

Las estrategias y políticas públicas en materia de seguridad deben ser evaluadas desde la perspectiva de los derechos humanos. Sólo a través de una ética pública, basada en el respeto a la dignidad y a los derechos y libertades 
fundamentales, podremos cruzar esta ola de inseguridad y violencia que desafortunadamente se ha generalizado en gran parte de América Latina.

Desde esta perspectiva, la solución que se plantea radica en una nueva cultura gubernamental de los derechos humanos. Esto quiere decir que todos los servidores públicos, independientemente del rango y de las funciones que desempeñen, deben conocer y entender los derechos humanos. De esta manera, estarán en posibilidades de llevar a cabo sus funciones con ética y con respeto a estos mínimos vitales.

Esta propuesta tiene un trasfondo relativamente sencillo, pero aún no se ha logrado establecer en la praxis del Estado de derecho actual. Se trata pues de forjar, en primer lugar, ciudadanos honrados, que conozcan y respeten los derechos humanos para que, consecuentemente, tengamos servidores públicos éticos. De tal forma sería posible inhibir la reproducción de conductas corruptas.

El ejercicio de la función policial es indispensable para el desarrollo y progreso de los Estados y, de igual manera, constituye una herramienta valiosísima para el aseguramiento de las personas, de sus bienes y de la sociedad misma. Por ello, su resignificación desde el ámbito de los derechos humanos, a través de la implantación de una cultura y de la ética pública, debe ser una tarea de urgencia en las agendas estatales.

\section{Referencias}

“Acción de Inconstitucionalidad 25/2016 y sus acumuladas 27/2016 y 28/2016”, Suprema Corte de Justicia de la Nación. [Consulta: noviembre, 2017]. Disponible en: https://www.scjn.gob.mx/sites/default/files/proyectos_resolucion_scjn/documento/2017-02/ACCION\%20INCONS\%20\%2027\%20Y\%2028\%20ACUMULADAS\%20DEFINITIVA\%20A\%20PUBLICAR_0.pdf

Alto Comisionado de las Naciones Unidas para los Refugiados, "Con 68 millones de personas desplazadas, es urgente un pacto mundial sobre refugiados", Alto Comisionado de las Naciones Unidas para los Refugiados. [Consulta: junio, 2018]. Disponible en: http://www.acnur.org/noticias/press/2018/6/5b29091d4/con-68-millones-de-personas-desplazadas-es-urgente-un-pacto-mundial-sobre.html

Álvarez, Alejandro, "El estado de la seguridad en América Latina: una aproximación a la evaluación situacional e institucional de la seguridad ciudadana en la región", Programa de las Naciones Unidas para el Desarrollo - LAC SURF, 2006. [Consulta: octubre, 2017]. Disponible en: https://es.scribd.com/document/36299474/ EL-ESTADO-DE-LA-SEGURIDAD-EN-AMERICA-LATINA

Amnistía InTERNACIONAL, Informe 2017/18 Amnistía Internacional. La situación de los derechos humanos en el mundo, Londres, Amnistía Internacional, 2018, p. 314. 
[Consulta: junio, 2018]. Disponible en: https://www.amnesty.org/es/countries/ americas/mexico/report-mexico/

Asamblea Nacional Francesa, "Declaración de los Derechos del Hombre", Conseil Constitutionnel. [Consulta: octubre, 2017]. Disponible en: http://www.conseil-constitutionnel.fr/conseilconstitutionnel/root/bank_mm/espagnol/es_ddhc.pdf

Bernal Ballesteros, María José, "La tortura en México como desafío del Estado de derecho en el siglo xxi”, en Enrique Cruz Martínez y Mario Cruz Martínez (coords.), Perspectiva de los desafíos del Estado de derecho en el México del siglo XxI", México, Tirant lo Blanch, 2017.

Bernal Ballesteros, María José, Olvera García, Jorge y Uribe Arzate, Enrique, "Los derechos humanos en el contexto del Estado constitucional”, Dignitas, núm. 21.

Bernal Ballesteros, María José, Luces y sombras del ombudsman. Un estudio comparado entre México y España, Toluca, Comisión de Derechos Humanos del Estado de México - Universidade de Santiago de Compostela, 2015.

Betancourt Higareda, Felipe Carlos, "Injusticia, desigualdades estructurales, y la construcción del Estado de derecho en México”, en Enrique Cruz Martínez y Mario Cruz Martínez (coords.), Perspectiva de los desafíos del Estado de derecho en el México del siglo xxI", México, Tirant lo Blanch, 2017.

Bielsa, Rafael Antonio y Brenna, Ramón Gerónimo, Reforma de la justicia y nuevas tecnologías, Buenos Aires, Ad Hoc, 1996.

Burton, Wear John, Conflict: Resolution and provention, Londres, The Macmillan Press, 1990.

Comisión Interamericana de Derechos Humanos, Informe sobre seguridad ciudadana y derechos humanos, Comisión Interamericana de Derechos Humanos. [Consulta: octubre, 2017]. Disponible en: http://www.cidh.org/pdf\%20files/SEGURIDAD\%20 CIUDADANA\%202009\%20ESP.pdf

Comisión Nacional de los Derechos Humanos, Informe de Actividades del 1 de enero al 31 de diciembre de 2017, México, CNDH, 2018.

Consejo Nacional de Evaluación de la Política de Desarrollo Social, "Principales hallazgos de la evaluación de la política de desarrollo social 2018", Coneval. [Consulta: junio, 2018]. Disponible en: https://www.coneval.org.mx/Evaluacion/IEPSM/ IEPSM/Paginas/IEPDS_2018_principales_hallazgos.aspx

Cruz Martínez, Enrique, Por una nueva ética de lo público en México: Experiencias sobre el impacto de la corrupción en la eficiencia gubernamental, México, Fontamara - Universidad Autónoma del Estado de México, 2015.

Cruz Martínez, Mario, "Por una ética pública de la democracia en México: la cultura gubernamental de los derechos humanos", en Enrique Cruz Martínez (coord.), Por una nueva ética de lo público en México: Experiencias sobre el impacto de la corrupción en la eficiencia gubernamental, México, Fontamara - Universidad Autónoma del Estado de México, 2015.

Delgado Mallarino, Víctor Alberto, "Policía, derechos humanos y libertades individuales”, Revista del Instituto Interamericano de Derechos Humanos, núm. 17. 
DíAz, ELíAs, "Estado de derecho y legitimidad democrática”, en Miguel Carbonell, Wistano Orozco y Rodolfo Vázquez (coords.), Estado de derecho: concepto, fundamentos y democratización en América Latina, México, Siglo XXI, 2002.

Diego Bautista, Oscar, “¿Cómo abordar la corrupción? Una vía para su solución a través de la ética pública” en Colección cuadernos para prevenir y controlar la corrupción, Tomo 4, México, Poder Legislativo del Estado de México, 2017.

Ferrajoli, Luigi, Derechos y garantías: La ley del más débil, Madrid, Trotta, 2006.

GANDARIA, MANRIQUE, "Ejecuciones del crimen organizado aumentan 35\% en primer trimestre de 2018: Semáforo Delictivo”, El Sol de Toluca, 24 de abril, 2018. [Consultada: junio, 2018]. Disponible en: https://www.elsoldemexico.com.mx/ mexico/justicia/ejecuciones-del-crimen-organizado-aumentan-35-en-primer-trimestre-de-2018-semaforo-delictivo-1637991.html

Gil Márquez, Tomas, El sistema de seguridad pública en la constitución española de 1978, Memoria de la tesis doctoral, Universitat A.Oliba. [Consulta: octubre, 2017]. Disponible en: http://www.tdx.cat/bitstream/handle/10803/9364/Ttgm. pdf?sequence $=1$

Institute for Economics And PeAce, Índice de paz México 2018, México, IEP, p. 9. [Consulta: junio, 2018]. Disponible en: http://indicedepazmexico.org/wp-content/ uploads/2018/04/Indice-de-Paz-Mexico-2018.pdf

Instituto Latinoamericano y del Caribe de Planificación Económica y Social y Ministerio de Planificación y CoOPeración de la RePÚBlica de Chile, Guía para la identificación, preparación y evaluación de proyectos de seguridad pública, Santiago de Chile, Ilpes - Mideplan, 1998.

Instituto Nacional de Estadística y Geografía, "Encuesta Nacional de Seguridad Pública Urbana 2018”, Inegi. [Consulta: junio, 2018]. Disponible en: http://www.beta. inegi.org.mx/app/saladeprensa/noticia.html?id=4134

Instituto Nacional de Estadística y Geografía, "Estadística a propósito de los policías y agentes de tránsito”, Inegi. [Consulta: noviembre, 2017]. Disponible en: http:// www.inegi.org.mx/saladeprensa/aproposito/2017/agentes2017_Nal.pdf

JAITMAn, LAURA, Los costos del crimen y de la violencia: nueva evidencia y hallazgos en América Latina y el Caribe, Washington, D. C., Banco Interamericano de Desarrollo, 2017, p. 98. [Consulta: noviembre, 2017]. Disponible en: https:// publications.iadb.org/bitstream/handle/11319/8133/Los-costos-del-crimen-yde-la-violencia-nueva-evidencia-y-hallazgos-en-America-Latina-y-el-Caribe. pdf?sequence $=8$

Jar Consuelo, Gonzalo, "El papel de la policía en una sociedad democrática”, Revista española de investigaciones sociales, núm. 85.

Kant, Immanuel, Fundamentación de la metafísica de la costumbre, Madrid, Ediciones Encuentro, 2003.

Márquez Rábago, Sergio, "El Estado de derecho en México”, en David Cienfuegos Salgado y Luis Gerardo Rodríguez Lozano (coords.), Estado, derecho y democracia en el momento actual. Contexto y crisis de las instituciones contemporáneas, 
Monterrey, Fondo editorial jurídico, 2008, pp. 211-230. [Consulta: noviembre, 2017]. Disponible en: https://archivos.juridicas.unam.mx/www/bjv/libros/6/2990/13.pdf

Martín del CAmpo, Labastida, Julio, "La transición del autoritarismo a la democracia en México”, en Miguel Carbonell Sánchez, Héctor Felipe Fix-Fierro, Luis Raúl González Pérez y Diego Valadés (coords.), Estado constitucional, derechos humanos, justicia y vida universitaria. Estudios en homenaje a Jorge Carpizo. Estado constitucional, tomo 4, vol. 2, México, Universidad Nacional Autónoma de México, 2015.

"Migración: De la obsesión por los riesgos, a aprovechar las oportunidades", Noticias onU, 11 de enero, 2018. [Consulta: junio, 2018]. Disponible en: https://news. un.org/es/story/2018/01/1424892

NAESSEns, HildA, “Ética pública y transparencia”, en 200 años de Iberoamérica (18102010) Congreso internacional, Santiago de Compostela, Universidade de Santiago de Compostela, 2010.

Otero Parga, Milagros, Estudios de derechos humanos: Introducción a los derechos humanos, objeción de conciencia y ética judicial, Toluca, Comisión de Derechos Humanos del Estado de México, 2003.

Oficina de las Naciones Unidas Contra la Droga y el Delito, Policía 2: integridad y responsabilidad de la policia. Manual de instrucciones para la evaluación de la justicia penal, Nueva York, Naciones Unidas, 2010, p. 1. [Consulta: octubre, 2017]. Disponible en: https://www.unodc.org/documents/justice-and-prison reform/ crimeprevention/The_Integrity_and_Accountability_of_the_Police_Spanish. pdf

Organización DE las Naciones Unidas, “Resolución 34/169”, Organización de las Naciones Unidas, 17 de diciembre, 1979. [Consulta: octubre, 2017]. Disponible en: https:// www.ohchr.org/SP/ProfessionalInterest/Pages/LawEnforcementOfficials.aspx

Organización de las Naciones Unidas, "Principios Básicos sobre el Empleo de la Fuerza y de Armas de Fuego por los Funcionarios Encargados de Hacer Cumplir la Ley”, Organización de las Naciones Unidas, La Habana, Cuba, 7 de septiembre, 1990. [Consulta: noviembre, 2017]. Disponible en: http://www.ohchr.org/SP/ProfessionalInterest/Pages/UseOfForceAndFirearms.aspx

Pavarini, Massimo, Pérez Carrillo, Agustín y Tenorio Tagle, Fernando, Seguridad Pública. Tres puntos de vista convergentes, México, Flasud - Conacyt - Ediciones Coyoacán, 2006.

Pring, CoRAlie, Las personas y la corrupción: América Latina y el Caribe. Barómetro Global de la Corrupción, Berlín, Transparency International, 2017, p. 9. [Consulta: noviembre de 2017]. Disponible en: http://www.libertadciudadana.org/ archivos/BAROMETR02017/LAC\%20GCB\%20SP_9_October_2017.pdf

Programa de las Naciones Unidas para el Desarrollo, Desarrollo humano en Chile. Las paradojas de la modernización, Santiago de Chile, PNUD, 1998. 
Ramírez Ramírez, EFrén, Los derechos humanos en la formación de la policía judicial. Manual de capacitación, México, Procuraduría General de Justicia del Distrito Federal e Instituto Nacional de Ciencias Penales, 2005.

RoBledo MAdRID, Wilfrido, “Uso de la fuerza pública, ¿Cómo y cuándo utilizarla?”, en $E l$ uso de la fuerza pública en un estado democrático de Derecho. Memoria del Congreso internacional, México, Instituto Nacional de Ciencias Penales, 2011.

Roccatti, Mireille, Los derechos humanos y la experiencia del ombudsman en México, Toluca, Comisión de Derechos Humanos del Estado de México, 1996.

Sotelo Regil, Luis, Policía profesional, México, Limusa, 2000.

Transparency International, "Índice de Percepción de la Corrupción 2017 de Transparency International América”, Transparency International, 2018. [Consulta: junio, 2018]. Disponible en: https://transparencia.org.es/wp-content/ uploads/2018/02/america_ipc-2017.pdf

Valencia Ramírez, Verónica GuadaluPe, "La seguridad pública como derecho humano", en Certamen de ensayo sobre derechos humanos, Toluca, Comisión de Derechos Humanos del Estado de México - Legislatura del Estado de México, 2002.

Valero, Ricardo, "La seguridad colectiva en América Latina", en Manuel Becerra Ramírez y Nuria González Martín (coords.), Estado de Derecho Internacional, México, Universidad Nacional Autónoma de México, 2012. 